\title{
Oxygen therapy in patients with ST elevation myocardial infarction based on the culprit vessel: results from the randomized controlled SOCCER trial
}

Arash Mokhtari ${ }^{1}$, Mahin Akbarzadeh², David Sparv ${ }^{1}$, Pallonji Bhiladvala ${ }^{3}$, Håkan Arheden $^{4}$, David Erlinge ${ }^{1}$ and Ardavan Khoshnood ${ }^{2^{*}}$ (D)

\begin{abstract}
Background: Oxygen $\left(\mathrm{O}_{2}\right)$ treatment has been a cornerstone in the treatment of patients with myocardial infarction. Recent studies, however, state that supplemental $\mathrm{O}_{2}$ therapy may have no effect or harmful effects in these patients. The aim of this study was thus to evaluate the effect of $\mathrm{O}_{2}$ therapy in patients with ST Elevation Myocardial Infarction (STEMI) based on the culprit vessel; Left Anterior Descending Artery (LAD) or Non-LAD.

Methods: This was a two-center, investigator-initiated, single-blind, parallel-group, randomized controlled trial at the Skåne university hospital, Sweden. A simple computer-generated randomization was used. Patients were either randomized to standard care with $\mathrm{O}_{2}$ therapy $(10 \mathrm{l} / \mathrm{min})$ or air until the end of the primary percutaneous coronary intervention. The patients underwent a Cardiac Magnetic Resonance Imaging (CMRI) days 2-6. The main outcome measures were Myocardium at Risk (MaR), Infarct Size (IS) and Myocardial Salvage Index (MSI) as measured by CMRI, and median high-sensitive troponin T (hs-cTnT).
\end{abstract}

Results: A total of 229 patients were assessed for eligibility, and 160 of them were randomized to the oxygen or air arm. Because of primarily technical problems with the CMRI, 95 patients were included in the final analyses; 46 in the oxygen arm and 49 in the air arm. There were no significant differences between patients with LAD and NonLAD as culprit vessel with regard to their allocation (oxygen or air) with regards to MSI, MaR, IS and hs-cTnT.

Conclusion: The results indicate that the location of the culprit vessel has probably no effect on the role of supplemental oxygen therapy in STEMI patients.

Trial registration: Swedish Medical Products Agency (EudraCT No. 2011-001452-11) and ClinicalTrials.gov Identifier (NCT01423929).

Keywords: ST elevation myocardial infarction, Oxygen, Myocardial infarction, Left anterior descending artery, Cardiac magnetic resonance imaging, Myocardium at risk, Infarct size, Myocardial salvage index, High-sensitive troponin T, Randomized controlled trials

\footnotetext{
* Correspondence: ardavan.khoshnood@med.lu.se

${ }^{2}$ Department of Clinical Sciences Lund, Emergency and Internal Medicine,

Lund University, Skåne University Hospital, Akutmottagningen, EA10, SUS

Lund, 22185 Lund, Sweden

Full list of author information is available at the end of the article
}

(c) The Author(s). 2020 Open Access This article is distributed under the terms of the Creative Commons Attribution 4.0 International License (http://creativecommons.org/licenses/by/4.0/), which permits unrestricted use, distribution, and reproduction in any medium, provided you give appropriate credit to the original author(s) and the source, provide a link to the Creative Commons license, and indicate if changes were made. The Creative Commons Public Domain Dedication waiver (http://creativecommons.org/publicdomain/zero/1.0/) applies to the data made available in this article, unless otherwise stated. 


\section{Background}

In a letter in 1859, Dr. Birch stated that even though oxygen therapy has an important role in the field of medicine, it should be used with caution [1]. Four decades later, Dr. Charles Steele, presented a case in which a patient with suspected angina had a relief of chest pain when treated with supplemental oxygen $\left(\mathrm{O}_{2}\right)$ [2]. Ever since, supplemental $\mathrm{O}_{2}$ therapy has been an important treatment in patients with chest pain and suspected myocardial infarction (MI).

Because of contradicting results and small studies, the cardiovascular effects of supplemental $\mathrm{O}_{2}$ therapy in canines, healthy individuals as well as individuals with $\mathrm{MI}$ was for a long time unclear [3]. Recent randomized controlled trials (RCT) on patients with suspected [4-6] as well as confirmed MI [7] and ST Elevation Myocardial Infarction (STEMI) [8-14] have however shown no positive nor negative cardiovascular effects of supplemental $\mathrm{O}_{2}$ therapy. Consequently, both the current guideline of the European Society of Cardiology for the management of STEMI [15], as well as the recently published British Medical Journal rapid recommendation on oxygen therapy [16], recommend that supplemental $\mathrm{O}_{2}$ therapy should not be administrated in patients with MI and a blood oxygen saturation of $\geq 90 \%$.

None of the above RCTs have however evaluated the effects of supplemental $\mathrm{O}_{2}$ therapy in patients with STEMI based on the culprit vessel. It has been shown that Left Anterior Descending (LAD) infarction results in both a larger myocardium at risk and a larger infarct size [17] in comparison to non-LAD infarctions. As supplemental $\mathrm{O}_{2}$ therapy has been suggested to increase oxygen delivery [18-22], it could thereby theoretically have a role in LAD infarcts. There are also studies that have shown potential harm with oxygen therapy with reduced coronary blood flow [23-26], why an adverse effect on infarct size could also be considered. It is therefore unknown whether $\mathrm{O}_{2}$ therapy might have a role in patients where the culprit vessel is the LAD artery. In this sub-study of the Supplemental Oxygen in Catheterized Coronary Emergency Reperfusion (SOCCER) trial, we therefore aimed to study the effects of supplemental $\mathrm{O}_{2}$ therapy in STEMI patients with regard to Myocardial Salvage Index (MSI), Myocardium at Risk (MaR), and Infarct Size (IS) based on whether the culprit vessel was the LAD or not. Our hypothesis was that $\mathrm{O}_{2}$ therapy would not provide a significant benefit even in LAD infarcts.

\section{Methods}

The current research is a sub-study of the SOCCER trial. The trial was a two-center, investigator-initiated, singleblind, parallel-group, randomized controlled trial and was carried out between 23 January 2012 and 5 August
2015 at the Skåne University Hospital in Lund and Malmö in Region Skåne, southern Sweden.

The trial was approved by both the Swedish Medical Product Agency and the Regional Ethical Review Board in Lund.

The current sub-study is reported in accordance with the CONSORT statement [27]. The methods of the trial will only be briefly discussed and described, since it has been described in detail previously [10, 11, 28].

\section{Study design and study setting}

The Skåne University Hospital in Malmö and Lund each have a 24-h emergency department with a total patient census of 150,000 annually.

After being dispatched to a patient with chest pain, the ambulance personal record an electrocardiogram (ECG) and transmit it to the nearest Cardiac Care Unit (CCU) where the physician on call interprets it. If deemed to be a STEMI, the patient is brought directly to the catheterization laboratory for Primary Percutaneous Coronary Intervention (PPCI). If the angiogram showed no lesion thus no PPCI was conducted, the patient would still be included in the final analysis.

The trial planned to include 100 patients. Inclusion criteria were normoxemic (blood $\mathrm{O}_{2}$ saturation $\geq 94 \%$ ) first time STEMI patients accepted for PPCI with a symptom duration of less than $6 \mathrm{~h}$, also being able to give an informed consent. Exclusion criteria were subsequently inability to make any decision of participating, previous myocardial infarction as well as, in regard to CMRI, significant claustrophobia or having magnetic materials inside the body. The patients were randomized in the ambulance to either standard $\mathrm{O}_{2}$ therapy in accordance with the ambulance guidelines in Region Skåne $\left(101 \mathrm{O}_{2} / \mathrm{min}\right)$ or no supplemental $\mathrm{O}_{2}$ therapy to be given through an OxyMask until the end of the PPCI. On days 2-6 after the PPCI, all included patients underwent a CMRI to determine MaR, IS and MSI.

Patients were randomized 1:1 to one of the two arms using block sizes of six. The blocks contained information on patient allocation based on computer-generated random numbers.

\section{Patient management}

Both the ambulance personnel as well as the PCI laboratory personnel registered patient management on case report forms. Other in-hospital data including the results of the PPCI were retrieved from patient records of Region Skåne (Melior; Siemens, Erlangen, Germany) and from the SWEDEHEART quality registries RIKS-HIA and SCAAR (http://www.ucr.uu.se/swedeheart/).

Except for the randomization and thus treatment with supplemental or no supplemental $\mathrm{O}_{2}$, all patients were treated and managed in accordance with international 
and national guidelines for the treatment of STEMI in both the pre-hospital and in-hospital setting [29-31].

\section{Culprit vessel}

The culprit vessel was defined as the coronary artery responsible for the ischemic event as identified by the interventional cardiologist performing the coronary angiography.

As the results of the angiography are not available to the physician upon first medical contact, the infarct location as determined by the initial ECG were also evaluated [32]. For this analysis the infarct location was divided into anterior/anteroseptal/anterolateral (AAA) or non-anterior/ anteroseptal/anterolateral (N-AAA), with AAA assumed to be due to LAD culprit, and N-AAA to non-LAD. The initial ECG assessment by the CCU physician was retrieved. All ECGs were then also independently interpreted by one of the study authors (AK) and if not in accordance with the interpretation of the CCU physician, they were analyzed by another of the study authors (AM). Both AK and AM were blinded to the group allocation of the patients.

\section{Cardiac magnetic resonance imaging}

Included patients underwent CMRI in either Lund (Philips 1.5 T Achieva, Best, Netherlands or Siemens 1.5 T Aera, Erlangen, Germany) or Malmö (Siemens $1.5 \mathrm{~T}$ Avanto, Erlangen, Germany) in two-chamber, fourchamber and LV outflow tract views (long-axis images) as well as short-axis images covering the LV. Details of the CMRI have previously been published [11].

In short, we quantified the MaR (the ischemic area before the PCI), the IS, and the MSI calculated as (1 - IS/ $\mathrm{MaR}) \times 100 \%$. Images from the CMR were assessed in the short-axis images after administration of gadoteric acid.

There are different methodologies in quantifying the infarction in images from the CMR. We used a validated semi-automatic algorithm [33] showing no bias when compared to histochemical staining 7 days after a MI [34]. The images were analyzed using the postprocessing software Segment, v.1.9 R3084 [35] by a physician blinded to all data and the patient's study group allocation.

The primary outcome of the study was MSI. Secondary outcomes were $\mathrm{MaR}$, IS and median peak high

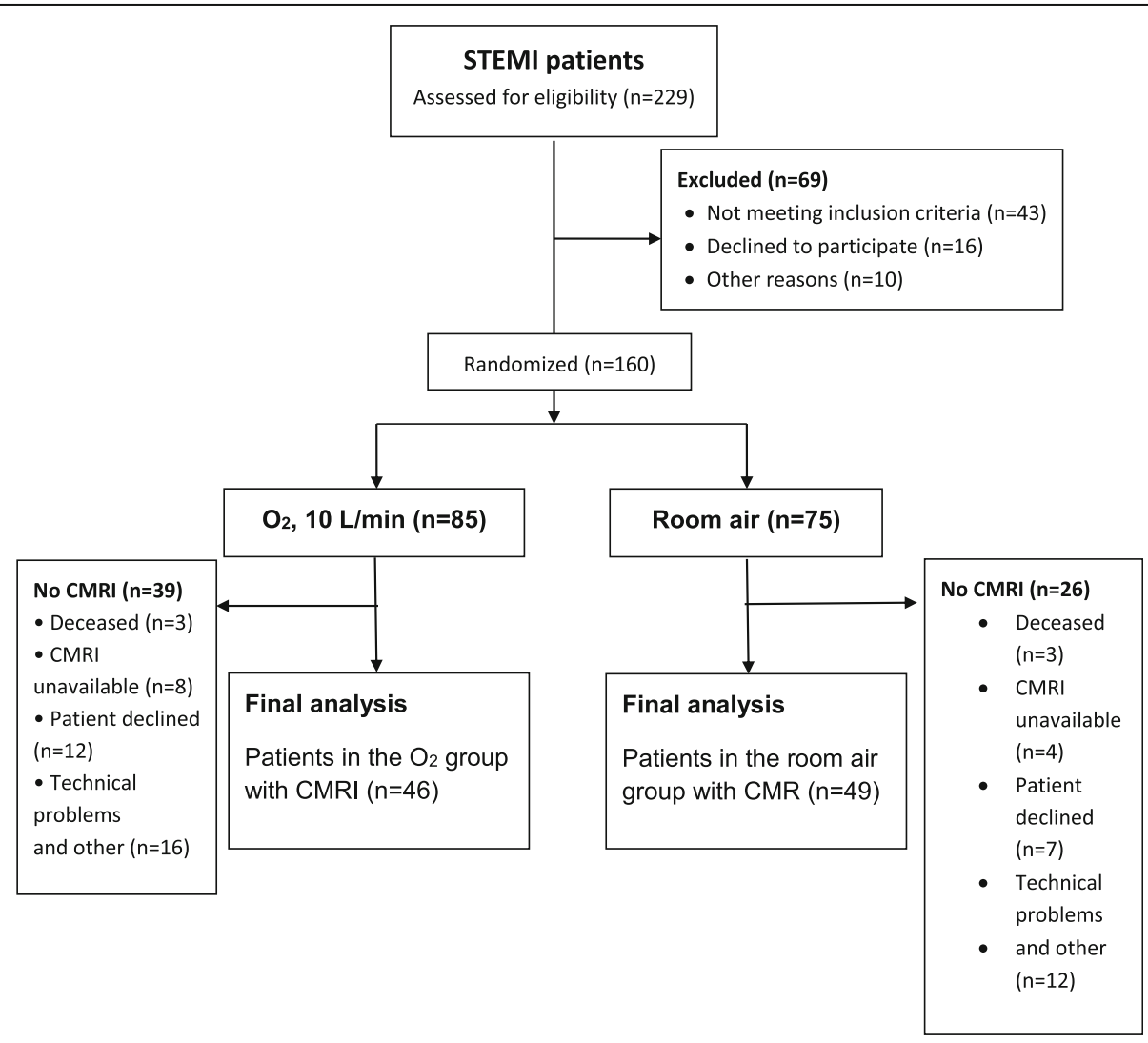

CMRI - Cardiac Magnetic Resonance Imaging; $\mathrm{O}_{2}$ - Oxygen; STEMI - ST Elevation Myocardial

Infarction

Fig. 1 Patient flow diagram 
Table 1 Patient and study characteristics for Cohort 1

\begin{tabular}{|c|c|c|c|}
\hline Characteristics & $\begin{array}{l}\mathrm{O}_{2} \text { group } \\
(n=46)\end{array}$ & $\begin{array}{l}\text { Air group } \\
(n=49)\end{array}$ & $P$-value \\
\hline \multicolumn{4}{|l|}{ Demographics } \\
\hline Male sex [n (\%)] & $29(63.0)$ & $34(69.4)$ & NS \\
\hline Age (year) [mean (SD)] & $63.7(13.1)$ & $65.5(11.5)$ & NS \\
\hline BMI [mean (SD)] & $26.1(3.4)$ & $27.0(4.2)$ & NS \\
\hline Smoker $^{\mathrm{a}}[\mathrm{n}(\%)]$ & $31(67.4)$ & $33(67.3)$ & NS \\
\hline \multicolumn{4}{|l|}{ Medical history [n (\%)] } \\
\hline Diabetes & $3(6.5)$ & $9(18.4)$ & NS \\
\hline Hypertension & $11(24.0)$ & $21(43.0)$ & NS \\
\hline Previous stroke/TIA & $0(0)$ & $3(6.1)$ & NS \\
\hline \multicolumn{4}{|l|}{ Previous medication [n (\%)] } \\
\hline ACEi & $8(17.4)$ & $5(10.2)$ & NS \\
\hline Anticoagulant & $1(2.2)$ & $0(0)$ & NS \\
\hline ARBs & $2(4.3)$ & $2(4.1)$ & NS \\
\hline Aspirin & $6(13.0)$ & $3(6.1)$ & NS \\
\hline$\beta$-blocker & $0(0)$ & $7(14.3)$ & NS \\
\hline$C C B$ & $1(2.2)$ & $7(14.3)$ & NS \\
\hline Diuretics & $1(2.2)$ & $7(14.3)$ & NS \\
\hline Statins & $2(4.3)$ & $5(10.2)$ & NS \\
\hline \multicolumn{4}{|l|}{ Process times (min) [mean (SD)] } \\
\hline Symptom to ambulance arrival & $110.9(112.6)$ & $98.2(87.8)$ & NS \\
\hline Symptom to $\mathrm{PCl}$ & $175.9(121.6)$ & $161.3(93.1)$ & NS \\
\hline Patient's home to PCl & $39.4(11.2)$ & $37.4(10.4)$ & NS \\
\hline \multicolumn{4}{|c|}{ Duration of study intervention $\left(\mathrm{O}_{2}\right.$ or room air) } \\
\hline Time (min) [mean (SD)] & $85.6(27.7)$ & $85.4(25.8)$ & NS \\
\hline $\begin{array}{l}\text { Intervention not for entire } \\
\text { duration [n (\%)] }\end{array}$ & $3(6.5)^{b}$ & $5(10.2)^{c}$ & NS \\
\hline \multicolumn{4}{|l|}{ Vital parameters at inclusion } \\
\hline Heart rate (BPM) [mean (SD)] & $84.2(17.3)$ & $82.7(18.2)$ & NS \\
\hline $\begin{array}{l}\text { Blood pressure }(\mathrm{mmHg}) \\
\text { [mean systolic pressure (SD)] }\end{array}$ & $154.0(29.6)$ & $153.7(29.1)$ & NS \\
\hline $\begin{array}{l}\text { Blood pressure }(\mathrm{mmHg}) \\
\text { [mean diastolic pressure (SD)] }\end{array}$ & $94.7(17.0)$ & $91.4(20.0)$ & NS \\
\hline $\begin{array}{l}\text { Blood oxygen saturation } \\
\text { [mean (SD)] }\end{array}$ & $98.0(1.7)$ & $97.7(1.6)$ & NS \\
\hline \multicolumn{4}{|c|}{ Vital parameters at arrival to the $\mathrm{PCl}$ laboratory } \\
\hline Heart rate (BPM) [mean (SD)] & $74(13.1)$ & $75(18.9)$ & NS \\
\hline $\begin{array}{l}\text { Blood pressure }(\mathrm{mmHg}) \\
\text { [mean systolic pressure (SD)] }\end{array}$ & $142.3(22.2)$ & $140.4(23.8)$ & NS \\
\hline $\begin{array}{l}\text { Blood pressure }(\mathrm{mmHg}) \\
\text { [mean diastolic pressure (SD)] }\end{array}$ & $85.3(15.3)$ & $84.8(14.6)$ & NS \\
\hline $\begin{array}{l}\text { Blood oxygen saturation } \\
\text { [mean (SD)] }\end{array}$ & $99.2(1.1)$ & $97.0(1.9)$ & $<0.001$ \\
\hline
\end{tabular}

Table 1 Patient and study characteristics for Cohort 1 (Continued)

\begin{tabular}{llll}
\hline Characteristics & $\begin{array}{l}\mathrm{O}_{2} \text { group } \\
(n=46)\end{array}$ & $\begin{array}{l}\text { Air group } \\
(n=49)\end{array}$ & $P$-value \\
\hline Killip class [n (\%)] & & & \\
Class I & $45(97.8)$ & $48(98.0)$ & NS \\
Class II & $1(2.2)$ & $1(2.0)$ & NS \\
\hline
\end{tabular}

ACEi Angiotensin Converting Enzyme Inhibitor, ARBs Angiotensin II Receptor Blockers, BMI Body Mass Index, BPM Beats Per Minute, CCB Calcium Channel Blocker, NS Not Significant, PCI Percutaneous Coronary Intervention, TIA Transitory Ischemic Attack

${ }^{\text {aBoth }}$ current and past smoker

${ }^{\mathrm{b}}$ The group allocation was unclear to the $\mathrm{PCl}$ personnel in two cases and in one case, the $\mathrm{O}_{2}$ therapy was terminated because the patient had chronic obstructive pulmonary disease

cAll patients received supplemental $\mathrm{O}_{2}$ due to fall in $\mathrm{O}_{2}$ saturation $<94 \%$

sensitivity troponin-T (hs-cTnT). We chose MSI as the primary endpoint as it has been shown to be highly related to the prognosis of a STEMI patient undergoing PPCI [36] and allows the evaluation of the effects of therapies using a smaller sample size [37].

\section{Statistical analysis}

For descriptive data, continuous variables are described with mean and standard deviation or median with interquartile range, and categorical variables are described with proportions.

Table 2 PCl laboratory procedural characteristics for Cohort 1

\begin{tabular}{|c|c|c|c|}
\hline Characteristics & $\begin{array}{l}\mathrm{O}_{2} \text { group } \\
(n=46)\end{array}$ & $\begin{array}{l}\text { Air group } \\
(n=49)\end{array}$ & $P$-value \\
\hline \multicolumn{4}{|l|}{ Medications given [n (\%)] } \\
\hline IV $\beta$-blocker & $3(6.5)$ & $5(10.2)$ & NS \\
\hline IV diuretics & $3(6.5)$ & $6(12.2)$ & NS \\
\hline IV inotropes & $0(0)$ & $1(2.0)$ & NS \\
\hline IV nitrate & $3(6.5)$ & $2(4.1)$ & NS \\
\hline \multicolumn{4}{|l|}{ Culprit lesion [n (\%)] } \\
\hline Right Coronary Artery & $18(39.1)$ & $20(40.8)$ & NS \\
\hline Left Anterior Descending Artery & $23(50.0)$ & $23(46.9)$ & NS \\
\hline Left Circumflex Artery & $4(8.7)$ & $3(6.1)$ & NS \\
\hline Other & $1(2.2)^{\mathrm{a}}$ & $3(6.1)^{b}$ & NS \\
\hline \multicolumn{4}{|l|}{ Coronary disease [n (\%)] } \\
\hline Single vessel & $25(54.3)$ & $29(59.2)$ & NS \\
\hline Multivessel & $20(43.4)$ & $17(34.7)$ & NS \\
\hline Left main coronary artery & $1(2.2)$ & $3(6.1)$ & NS \\
\hline \multicolumn{4}{|l|}{ Procedures [n (\%)] } \\
\hline Thrombectomy & $11(24.0)$ & $13(26.5)$ & NS \\
\hline CABG & $2(4.4)$ & $2(4.0)$ & NS \\
\hline
\end{tabular}

CABG Coronary Artery Bypass Grafting, IV Intravenous, SC Subcutaneous ${ }^{a}$ Culprit was the intermediate artery

${ }^{\mathrm{b}}$ Culprit in one case was the intermediate artery and in two cases the D1 branch of the LAD 
Table 3 CMRI results and the mean peak Troponin $T$ in relation to the culprit lesion

\begin{tabular}{|c|c|c|c|c|c|c|}
\hline \multirow[t]{2}{*}{ Measures [mean (SD)] } & \multicolumn{2}{|c|}{$\mathrm{O}_{2}$ group $(n=46)$} & \multicolumn{2}{|c|}{ Air group $(n=49)$} & \multicolumn{2}{|c|}{$P$-value for the difference } \\
\hline & $\operatorname{LAD}(n=23)$ & Non-LAD $(n=23)$ & $\operatorname{LAD}(n=23)$ & Non-LAD $(n=26)$ & LAD & Non-LAD \\
\hline MaR \% of LV & $36.3(10.8)$ & $27.5(6.7)$ & $36.9(12.1)$ & $23.9(7.4)$ & 0.717 & 0.081 \\
\hline MSI \% & $47.8(24.0)$ & $60.0(25.2)$ & $43.0(24.1)$ & $54.9(22.8)$ & 0.517 & 0.568 \\
\hline IS \% of LV & $19.4(10.7)$ & $11.9(8.9)$ & $19.4(10.7)$ & $10.9(7.0)$ & 0.448 & 0.787 \\
\hline IS ml & $26.2(17.3)$ & $15.1(11.5)$ & $26.2(17.3)$ & $13.3(9.4)$ & 0.733 & 0.696 \\
\hline hs-cTnT [median (IQR)] & $3319.0(5619.0)$ & $2760.0(3875.0)$ & $3862.0(7103.0)$ & $922.5(2793.3)$ & 0.717 & 0.062 \\
\hline
\end{tabular}

CMRI Cardiac Magnetic Resonance Imaging, hs-cTnT High-Sensitive Cardiac Troponin T, IS Infarct Size, IQR Interquartile range, LV Left Ventricle, MaR Myocardium at Risk, $m /$ Milliliters, MSI Myocardial Salvage Index, $\mathrm{O}_{2}$ Oxygen, SD Standard Deviation

The two arms of the trial were each divided into two sub-groups with respect to the culprit vessel; LAD and non-LAD. All data were analyzed using IBM SPSS Statistics (V22; Armonk, New York, USA). For differences in CMRI results between the two arms of the study, the two-sided Mann-Whitney test were used. To model the effects, linear regression with an interaction term was used. A $p$-value of less than 0.05 was considered to be statistically significant.

A power calculation for the main outcome of the SOCCER trial was performed based on the following assumptions. MSI is assumed to be $60 \pm 20 \%$ [38-41] in the standard treatment group, also known as the $\mathrm{O}_{2}$ group. Inclusion of a total sample of 100 patients in the study, allows for the detection of an MSI difference of $15 \%$ between the $\mathrm{O}_{2}$ group and the air group with a power of $96 \%$ at a $5 \%$ risk of a Type I error. Since the effect of the culprit vessel on the effectiveness of the $\mathrm{O}_{2}$ therapy was considered a secondary outcome, no formal power calculation was conducted for this outcome.

\section{Results}

Figure 1 displays the study profile. Of the 229 patients screened, 160 were randomized to either the supplemental $\mathrm{O}_{2}$ group $(n=85)$ or to the air group $(n=75)$. Of the included patients in the two arms, $54 \%(n=46)$ and $65 \%$ $(n=49)$ respectively underwent a CMRI.

The majority of the patients included were male, and most of the included patients either smoked or were previous smokers (Table 1). The mean duration of the study intervention for both groups were $85 \mathrm{~min}$, as symptom debut to PCI were on average $161 \mathrm{~min}$ (the air

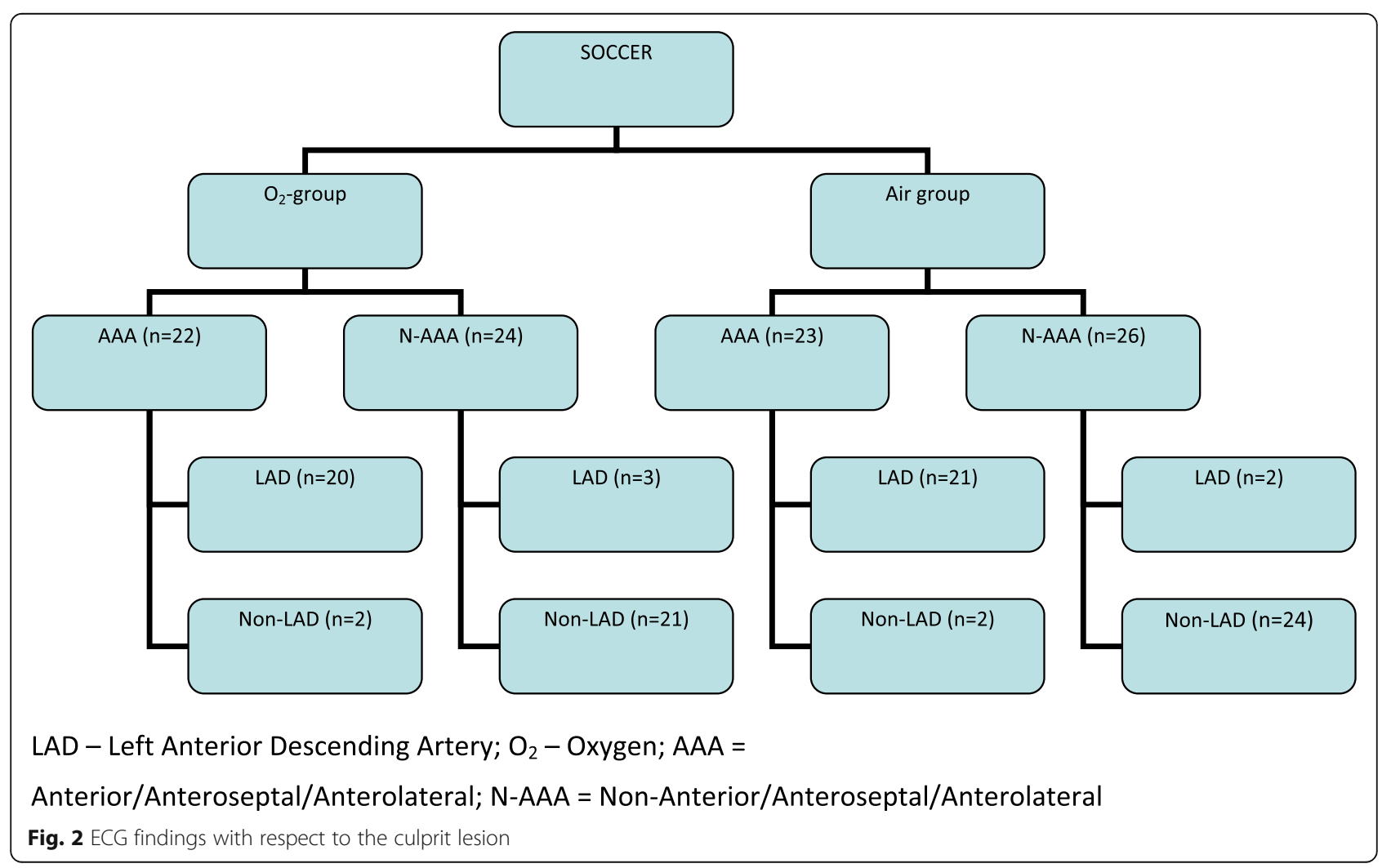


Table 4 CMRI results and the median peak Troponin $T$ in relation to the ECG findings

\begin{tabular}{|c|c|c|c|c|c|c|}
\hline \multirow[t]{2}{*}{ Measures [mean (SD)] } & \multicolumn{2}{|c|}{$\mathrm{O}_{2}$ group $(n=46)$} & \multicolumn{2}{|c|}{ Air group $(n=49)$} & \multicolumn{2}{|c|}{$P$-value for the difference } \\
\hline & $\operatorname{AAA}(n=22)$ & $\mathrm{N}-\mathrm{AAA}(n=24)$ & $\operatorname{AAA}(n=23)$ & Non-AAA $(n=26)$ & AAA & N-AAA \\
\hline MaR \% of LV & $34.8(10.8)$ & $29.2(8.4)$ & $37.1(11.9)$ & $23.7(7.5)$ & 0.401 & 0.021 \\
\hline MSI \% & $48.8(25.3)$ & $58.6(24.5)$ & $47.9(26.9)$ & $50.6(21.3)$ & 0.964 & 0.286 \\
\hline IS \% of LV & $18.6(11.2)$ & $13.0(9.1)$ & $20.7(13.0)$ & $11.8(6.6)$ & 0.482 & 0.641 \\
\hline IS ml & $25.0(17.5)$ & $16.6(12.6)$ & $26.8(19.2)$ & $14.2(9.1)$ & 0.803 & 0.560 \\
\hline hs-cTnT [median (IQR)] & $3487.5(6035.3)$ & $3039.0(3705.8)$ & $3862.0(7458.0)$ & $1079.0(2726.5)$ & 0.910 & 0.074 \\
\hline
\end{tabular}

$A A A$ Anterior/Anteroseptal/Anterolateral, CMRI Cardiac Magnetic Resonance Imaging, $h s-c T n T$ High-Sensitive Cardiac Troponin T, IS Infarct Size, IQR Interquartile range, $L V$ Left Ventricle, MaR Myocardium at Risk, $m /$ Milliliters, MSI Myocardial Salvage Index, $\mathrm{O}_{2}$ Oxygen, $N$ - $A A A$ Non-Anterior/Anteroseptal/Anterolateral, SD Standard Deviation

group) and $175 \mathrm{~min}$ (the $\mathrm{O}_{2}$ group). There were no significant differences in oxygen saturation at the time of randomization, while the oxygen saturation was higher in the $\mathrm{O}_{2}$ group during the intervention $(99.2 \%$ vs $97.0 \%$, $p<0.001)$. There were no other significant differences in baseline characteristics between the two groups, but a somewhat higher proportion of patients in the air group had diabetes and hypertension, while symptom debut to ambulance arrival/PCI times were somewhat higher in the $\mathrm{O}_{2}$ group.

The majority in both groups had a single vessel disease, and close to a quarter of the included patients in both groups had a thrombectomy (Table 2). There were no significant differences between the two groups with regard to the culprit vessel, with LAD being the most common culprit vessel in both the $\mathrm{O}_{2}$ group $(n=23$, $50 \%)$ as well as the air group $(n=23,46.9 \%)$, followed by the RCA. Only four patients in the $\mathrm{O}_{2}$ group and three patients in the air group had the LCx as the culprit vessel.

Table 3 shows the results of the CMRI for the both randomization groups. There was no significant difference in MSI among patients with a LAD culprit depending on allocation to $\mathrm{O}_{2}$ or air $(47.8 \%$ vs $43.0 \% ; p=$ 0.517). There were also no significant differences with regards to MaR, IS or hs-cTnT levels. Among the patients with a non-LAD culprit, there were no significant differences between the $\mathrm{O}_{2}$ or air group for neither the primary nor the secondary outcomes.

Figure 2 shows the corresponding angiographic culprit vessel depending on the ECG pattern. As shown in
Table 4, there were no significant differences with regards to the primary outcome between patients randomized to $\mathrm{O}_{2}$ or air based on the ECG STEMI pattern. There were also no significant differences for the secondary outcomes, except for MaR which was significantly larger among N-AAA patients randomized to the $\mathrm{O}_{2}$ group vs air $(29.2 \%$ vs $23.7 \% ; p=0.021)$.

We also evaluated the effect of supplemental $\mathrm{O}_{2}$ therapy by subgroup with respect to both the culprit vessel (Table 5) and ECG finding (Table 6), using multiple regression with an interaction term. No significant effect of $\mathrm{O}_{2}$ therapy was found in any group for any outcome.

\section{Discussion}

In this sub-study of the SOCCER trial, we evaluated the effects of supplemental $\mathrm{O}_{2}$ therapy in STEMI patients with regard to MSI, MaR, and IS based on the culprit vessel (Fig. 3). Our main finding was that there is no significant difference between the patients randomized to the $\mathrm{O}_{2}$ group or the air group based on the location of the culprit vessel as identified by the interventional cardiologist performing the coronary angiography. The same results could also be shown based on the ECG STEMI pattern. Although MaR was significantly larger in the $\mathrm{O}_{2}$ group among N-AAA patients, this is somewhat hard to explain on a theoretical basis and likely due to chance alone.

In the AVOID trial [14] in which 441 STEMI patients were randomized to $\mathrm{O}_{2}$ therapy or air, there was a significant increase in Creatine Kinase (CK) levels in the $\mathrm{O}_{2}$ group, with a similar trend shown among STEMI

Table 5 CMRI Linear Regression and the culprit vessel

\begin{tabular}{|c|c|c|c|c|c|c|c|c|c|c|}
\hline \multirow[t]{2}{*}{ Variables } & \multicolumn{2}{|l|}{ MSI \% } & \multicolumn{2}{|l|}{ MaR \% of LV } & \multicolumn{2}{|l|}{ IS \% of LV } & \multicolumn{2}{|l|}{ IS ml } & \multicolumn{2}{|l|}{ hs-cTnT } \\
\hline & Coefficient (Cl) & $p$-value & Coefficient (Cl) & $p$-value & Coefficient (Cl) & $p$-value & Coefficient (Cl) & $p$-value & Coefficient (Cl) & $p$-value \\
\hline $\begin{array}{l}\text { Effect of } \mathrm{O}_{2} \text { in } \\
\text { LAD-group }\end{array}$ & $\begin{array}{l}4.82 \\
(-9.23 ; 18.87)\end{array}$ & 0.497 & $\begin{array}{l}-0.66 \\
(-6.22 ; 4.89)\end{array}$ & 0.813 & $\begin{array}{l}-2.26 \\
(-7.96 ; 3.45)\end{array}$ & 0.434 & $\begin{array}{l}-1.65 \\
(-10.13 ; 6.83)\end{array}$ & 0.700 & $\begin{array}{l}-584.4 \\
(-2502.9 ; 1334.1)\end{array}$ & 0.547 \\
\hline $\begin{array}{l}\text { Effect of } \mathrm{O}_{2} \text { in } \\
\text { non-LAD-group }\end{array}$ & $\begin{array}{l}5.09 \\
(-8.55 ; 18.73)\end{array}$ & 0.460 & $\begin{array}{l}3.58 \\
(-1.81 ; 8.98)\end{array}$ & 0.190 & $\begin{array}{l}0.97 \\
(-4.57 ; 6.50)\end{array}$ & 0.729 & $\begin{array}{l}1.79 \\
(-6.45 ; 10.01)\end{array}$ & 0.668 & $\begin{array}{l}1039.0 \\
(-823.3 ; 2901.3)\end{array}$ & 0.271 \\
\hline
\end{tabular}

hs-cTnT High sensitive cardiac troponin T, IS Infarct Size, LAD Left Anterior Descending artety, LV Left Ventricle, MaR Myocardium at Risk, MSI Myocardial Salvage Index, $\mathrm{O}_{2}$ Oxygen 
Table 6 CMRI Linear regression and ECG findings

\begin{tabular}{|c|c|c|c|c|c|c|c|c|c|c|}
\hline \multirow[t]{2}{*}{ Variables } & \multicolumn{2}{|l|}{ MSI \% } & \multicolumn{2}{|l|}{ MaR $\%$ of LV } & \multicolumn{2}{|l|}{ IS \% of LV } & \multicolumn{2}{|l|}{$\mathrm{IS} \mathrm{ml}$} & \multicolumn{2}{|l|}{ hs-cTnT } \\
\hline & Coefficient (CI) & $\overline{p \text {-value }}$ & Coefficient (Cl) & $\overline{p \text {-value }}$ & Coefficient $(\mathrm{Cl})$ & $\overline{p \text {-value }}$ & Coefficient (Cl) & $\overline{p \text {-value }}$ & Coefficient (Cl) & $p$-value \\
\hline $\begin{array}{l}\text { Effect of } \mathrm{O}_{2} \text { in } \\
\text { AAA-group }\end{array}$ & $\begin{array}{l}0.90 \\
(-13.60 ; 15.41)\end{array}$ & 0.902 & $\begin{array}{l}-2.298 \\
(-8.06 ; 3.47)\end{array}$ & 0.430 & $\begin{array}{l}-2.17 \\
(-8.17 ; 3.84)\end{array}$ & 0.475 & $\begin{array}{l}-1.77 \\
(-10.61 ; 7.08)\end{array}$ & 0.693 & $\begin{array}{l}-474.4 \\
(-2427.1 ; 1478.4)\end{array}$ & 0.631 \\
\hline $\begin{array}{l}\text { Effect of } \mathrm{O}_{2} \text { in } \\
\mathrm{N} \text {-AAA-group }\end{array}$ & $\begin{array}{l}8.03 \\
(-5.74 ; 21.79)\end{array}$ & 0.250 & $\begin{array}{l}5.44 \\
(-0.03 ; 10.92)\end{array}$ & 0.051 & $\begin{array}{l}1.23 \\
(-4.47 ; 6.93)\end{array}$ & 0.669 & $\begin{array}{l}2.38 \\
(-6.01 ; 10.78)\end{array}$ & 0.077 & $\begin{array}{l}962.8 \\
(-890.8 ; 2816.4)\end{array}$ & 0.305 \\
\hline
\end{tabular}

AAA Anterior/Anteroseptal/Anterolateral, hs-cTnT High sensitive cardiac troponin T, IS Infarct Size, LAD Left Anterior Descending artety, LV Left Ventricle, MaR Myocardium at Risk, MSI Myocardial Salvage Index, $\mathrm{O}_{2}$ Oxygen

patients with an LAD and non-LAD culprit. In our study we however did analysis based on culprit vessel using MaR, IS, and MSI as measured by CMR, which are superior to CK levels for assessing infarct size and myocardial injury as well as prognosis [38, 42-44], and could not see any significant differences between the $\mathrm{O}_{2}$ and air groups.

The DETO2X-AMI trial conducted in Sweden had allcause mortality at 1 year as the primary outcome and included more than 6000 patients with suspected MI who were randomized to either $\mathrm{O}_{2}$ therapy or air; the trial showed no difference between the groups [4]. A substudy of the trial focusing on STEMI patients $(n=2807)$ randomized to $\mathrm{O}_{2}$ therapy or air, also showed no differences between the groups in regard to one-year all-cause mortality or morbidity [8]. They did not however evaluate whether there were any differences based on culprit vessel.

In our previous publications $[9,10,28]$, we have evaluated the role of supplemental $\mathrm{O}_{2}$ in first time STEMI patients with respect to MSI, MaR and IS as measured by Cardiac Magnetic Resonance Imaging (CMRI), and Wall Motion Score Index and Left Ventricular Ejection Fraction as measured by Echocardiography [10, 28]. The results, in line with other trials, showed no negative nor positive effects of supplemental $\mathrm{O}_{2}$ therapy in regard to the studied outcomes. We have also previously shown that there does not seem to be a significant analgesic effect of $\mathrm{O}_{2}$ in patients with STEMI [9].

These findings were confirmed in a recent metaanalysis including eight RCTs studying the effects of supplemental $\mathrm{O}_{2}$ therapy in patients with suspected and confirmed MI $(n=7998)$, showing no clinical benefits [45]. In another meta-analysis including 25 RCTs and a total study population of 16,037 acutely ill patients, it was shown that supplemental $\mathrm{O}_{2}$ therapy in normoxemic (blood $\mathrm{O}_{2}$ saturation $\geq 94 \%$ ) patients increased mortality [46]. It is thus clear from the current evidence that supplemental $\mathrm{O}_{2}$ therapy should only be considered in patients with hypoxemia.

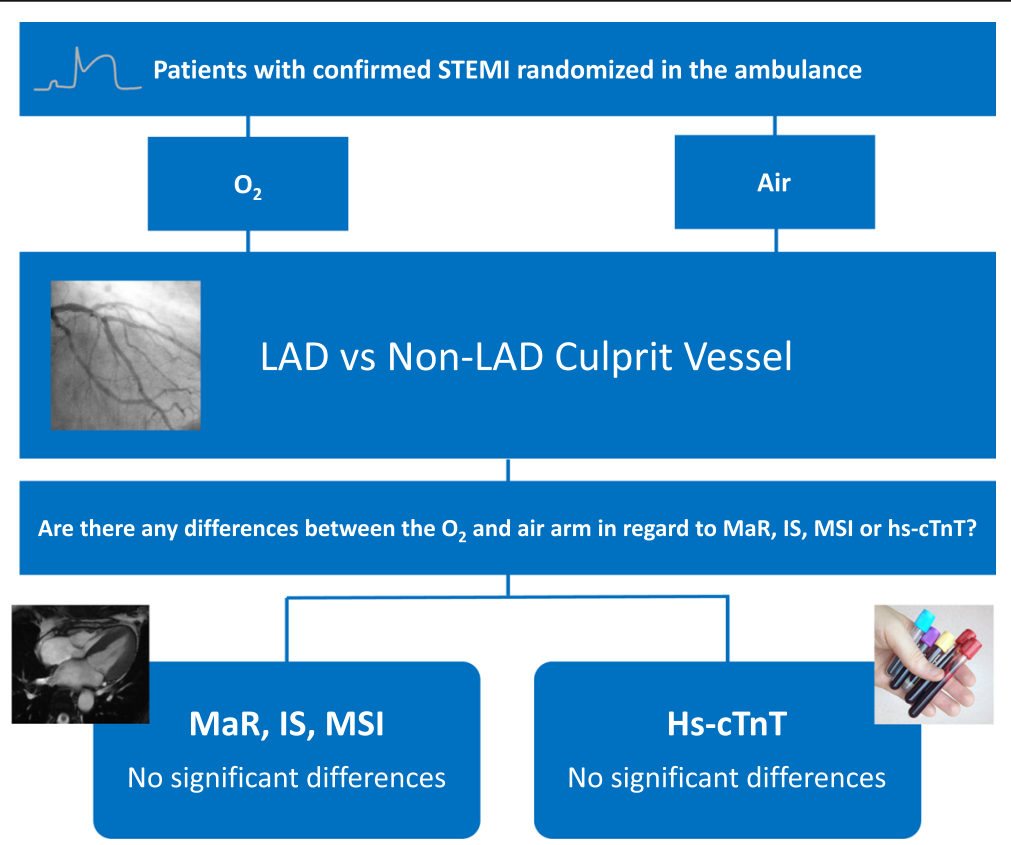

Fig. 3 Central Illustration 
Our results are thereby in line with previous studies showing no positive nor negative effects of supplemental $\mathrm{O}_{2}$ therapy in patients with confirmed or suspected MI, $[3,4,6,8-11,13,45]$ and this also seems to be the case irrespective of culprit vessel. It thereby seems safe to withhold oxygen in normoxic STEMI patients, irrespective of infarct location.

\section{Limitations}

Our results are only applicable to STEMI patients and not acute coronary syndrome patients as a whole as patients with non-STEMI and unstable angina were not included. Furthermore, since our results are from two centers only, they may not be generalizable to other settings. The included patients were also normoxic and hemodynamically stable, why our results may not be applicable to unstable STEMI patients. After allocating the included patients into different culprit vessel subgroups, the number of patients studied in each group were few why there may be some risk of type 2 error.

Since our primary outcome (MSI) and most of the secondary outcomes (MaR and IS) were solely based on patients undergoing CMRI, a drop-out of patients was inevitable. Although the dropout of patients may be a source of bias, the reasons for why some patients did not undergo CMRI were almost equal between the two groups (Fig. 1).

\section{Conclusion}

There were no significant differences in MSI, MaR, IS, or hs-cTnT levels between first time STEMI patients randomized to supplemental $\mathrm{O}_{2}$ therapy or air, in relation to whether the culprit vessel was the LAD or not. Our results thereby indicate that the location of the culprit vessel probably has no effect on the role of supplemental $\mathrm{O}_{2}$ therapy in STEMI patients.

\begin{abstract}
Abbreviations
AAA: Anterior/Anteroseptal/Anterolateral; CCU: Cardiac Care Unit; CMR: Cardiac Magnetic Resonance; CMRI: Cardiac Magnetic Resonance Imaging; ECG: Electrocardiogram; hs-cTnT: High Sensitive Troponin-T; IS: Infarct Size; LAD: Left Anterior Descending artery; MaR: Myocardium at Risk; MSI: Myocardial Salvage Index; N-AAA: Non-Anterior/Anteroseptal/ Anterolateral; $\mathrm{O}_{2}$ : Oxygen; PPCl: Primary Percutaneous Coronary Intervention; RCT: Randomized Controlled Trials; STEMI: ST Elevation Myocardial Infarction
\end{abstract}

\section{Acknowledgements}

We would like to express our very great appreciation to Axel Ström from Clinical Studies Sweden - Forum South, for his valuable statistical assistance. We would also like to thank our dear Dr. Peter Höglund (1956-2019) for his initial statistical assistance.

\section{Conflict of interest}

None.

\section{Authors' contributions}

Study concept and design: AM, MA, DS, PB, AK. Drafting of the manuscript: AM. Critical revision of the manuscript for important intellectual content: DS, $H A, D E, A K$. All authors read and approved the final manuscript.

\section{Funding}

This work was supported by independent research grants from the Swedish Heart-Lung Foundation and Lund University. The funding bodies had no role in the design of the study and collection, analysis, and interpretation of data and in writing the manuscript. Open access funding provided by Lund University.

\section{Availability of data and materials}

A de-identified dataset will be made available upon written reasonable request to the corresponding author.

\section{Ethics approval and consent to participate}

The Regional Ethical Review Board in Lund (Dnr 2011/258) approved the trial. All patients were informed about the trial and a written consent was obtained.

\section{Consent for publication}

Not applicable.

\section{Competing interests}

The authors declare that they have no competing interests.

\section{Author details}

${ }^{1}$ Department of Clinical Sciences Lund, Cardiology, Lund University, Skåne University Hospital, Lund, Sweden. 'Department of Clinical Sciences Lund, Emergency and Internal Medicine, Lund University, Skåne University Hospital, Akutmottagningen, EA10, SUS Lund, 22185 Lund, Sweden. ${ }^{3}$ Department of Cardiology, Skåne University Hospital, Malmö, Sweden. ${ }^{4}$ Department of Clinical Sciences Lund, Clinical Physiology, Lund University, Skåne University Hospital, Lund, Sweden.

Received: 12 June 2019 Accepted: 10 February 2020

Published online: 18 February 2020

\section{References}

1. Birch SB. On oxygen as a therapeutic agent. Br Med J. 1859;1(333):567-8.

2. Steele $C$. Severe angina pectoris relieved by oxygen inhalations. Br Med J. 1900;2(2083):1568

3. Khoshnood A. High time to omit oxygen therapy in ST elevation myocardial infarction. BMC Emerg Med. 2018;18(1):35.

4. Hofmann R, James SK, Jernberg T, Lindahl B, Erlinge D, Witt N, Arefalk G, Frick M, Alfredsson J, Nilsson L. Oxygen therapy in suspected acute myocardial infarction. N Engl J Med. 2017:377(13):1240-9.

5. Rawles J, Kenmure A. Controlled trial of oxygen in uncomplicated myocardial infarction. Br Med J. 1976;1(6018):1121-3.

6. Sparv D, Hofmann R, Gunnarsson A, James S, Hedberg C, Lauermann J, Torild $\mathrm{P}$, Omerovic E, Bergström $\mathrm{K}$, Haugen $\mathrm{E}$. The analgesic effect of oxygen in suspected acute myocardial infarction: a substudy of the DETO2X-AMI trial. JACC Cardiovasc Interv. 2018;11(16):1590-7.

7. Wilson A, Channer K. Hypoxaemia and supplemental oxygen therapy in the first 24 hours after myocardial infarction: the role of pulse oximetry. J R Coll Physicians Lond. 1997:31(6):657-61.

8. Hofmann R, Witt N, Lagerqvist B, Jernberg T, Lindahl B, Erlinge D, Herlitz J, Alfredsson J, Linder R, Omerovic E. Oxygen therapy in ST-elevation myocardial infarction. Eur Heart J. 2018;39(29):2730-9.

9. Khoshnood A, Akbarzadeh M, Carlsson M, Sparv D, Bhiladvala P, Mokhtari A Erlinge $D$, Ekelund $U$. Effect of oxygen therapy on chest pain in patients with ST elevation myocardial infarction: results from the randomized SOCCER trial. Scand CardiovasC J. 2018;52(2):69-73.

10. Khoshnood A, Akbarzadeh M, Roijer A, Meurling C, Carlsson M, Bhiladvala P, Höglund P, Sparv D, Todorova L, Mokhtari A. Effects of oxygen therapy on wall-motion score index in patients with ST elevation myocardial infarction - the randomized SOCCER trial. Echocardiography. 2017:34(8):1130-7

11. Khoshnood A, Carlsson M, Akbarzadeh M, Bhiladvala P, Roijer A, Nordlund D, Höglund P, Zughaft D, Todorova L, Mokhtari A. Effect of oxygen therapy on myocardial salvage in ST elevation myocardial infarction: the randomized SOCCER trial. Eur J Emerg Med. 2018;25(2):78-84.

12. Nehme Z, Stub D, Bernard S, Stephenson M, Bray JE, Cameron P, Meredith IT, Barger B, Ellims AH, Taylor AJ. Effect of supplemental oxygen exposure 
on myocardial injury in ST-elevation myocardial infarction. Heart. 2016; 102(6):444-51.

13. Ranchord AM, Argyle R, Beynon R, Perrin K, Sharma V, Weatherall M, Simmonds M, Heatlie G, Brooks N, Beasley R. High-concentration versus titrated oxygen therapy in ST-elevation myocardial infarction: a pilot randomized controlled trial. Am Heart J. 2012;163(2):168-75.

14. Stub D, Smith K, Bernard S, Nehme Z, Stephenson M, Bray JE, Cameron P, Barger B, Ellims AH, Taylor AJ. Air versus oxygen in ST-segment elevation myocardial infarction. Circulation. 2015;131(24):2143-50.

15. Ibanez B, James S, Agewall S, Antunes MJ, Bucciarelli-Ducci C, Bueno H, Caforio AL, Crea F, Goudevenos JA, Halvorsen S. 2017 ESC guidelines for the management of acute myocardial infarction in patients presenting with STsegment elevation: the task force for the management of acute myocardial infarction in patients presenting with ST-segment elevation of the European Society of Cardiology (ESC). Eur Heart J. 2017;39(2):119-77.

16. Siemieniuk RAC, Chu DK, Kim LH-Y, Güell-Rous M-R, Alhazzani W, Soccal PM, Karanicolas PJ, Farhoumand PD, Siemieniuk JLK, Satia I, et al. Oxygen therapy for acutely ill medical patients: a clinical practice guideline. Br Med J. 2018:363:k4169.

17. Nordlund D, Heiberg E, Carlsson M, Fründ E-T, Hoffmann P, Koul S, Atar D, Aletras AH, Erlinge D, Engblom H. Extent of myocardium at risk for left anterior descending artery, right coronary artery, and left circumflex artery occlusion depicted by contrast-enhanced steady state free precession and T2-weighted short tau inversion recovery magnetic resonance imaging. Circ Cardiovasc Imaging. 2016;9(7):e004376.

18. Ukholkina GB, Kuchkina NV, Grendo EP, Gofman I. Oxygen therapy in combination with endovascular reperfusion during the first hours of acute myocardial infarction: clinical and laboratory findings. Int J Interv Cardioangiol. 2005;9:45-51.

19. Madias J, Hood W Jr. Reduction of precordial ST-segment elevation in patients with anterior myocardial infarction by oxygen breathing. Circulation. 1976;53(3 Suppl):198.

20. Maroko PR, Radvany P, Braunwald E, Hale SL. Reduction of infarct size by oxygen inhalation following acute coronary occlusion. Circulation. 1975; 52(3):360-8

21. Saÿen JJ, Sheldon WF, Horwitz O, Kuo PT, Peirce G, Zinsser HF, Mead J Jr. Studies of coronary disease in the experimental animal. II. Polarographic determinations of local oxygen availability in the Dog's left ventricle during coronary occlusion and pure oxygen breathing. I Clin Invest. 1951:30(9):932-40.

22. Kelly RF, Hursey TL, Parrillo JE, Schaer GL. Effect of 100\% oxygen administration on infarct size and left ventricular function in a canine model of myocardial infarction and reperfusion. Am Heart J. 1995;130(5):957-65.

23. Guensch DP, Fischer K, Shie N, Lebel J, Friedrich MG. Hyperoxia exacerbates myocardial ischemia in the presence of acute coronary artery stenosis in swine. Circ Cardiovasc Interv. 2015;8(10):e002928.

24. Waring WS, Thomson AJ, Adwani SH, Rosseel AJ, Potter JF, Webb DJ, Maxwell SR. Cardiovascular effects of acute oxygen administration in healthy adults. J Cardiovasc Pharmacol. 2003;42(2):245-50.

25. Rousseau A, Bak Z, Janerot-Sjöberg B, Sjöberg F. Acute hyperoxaemiainduced effects on regional blood flow, oxygen consumption and central circulation in man. Acta Physiol Scand. 2005;183(3):231-40.

26. Bodetoft S, Carlsson M, Arheden $\mathrm{H}$, Ekelund U. Effects of oxygen inhalation on cardiac output, coronary blood flow and oxygen delivery in healthy individuals, assessed with MRI. Eur J Emerg Med. 2011;18(1):25-30.

27. Schulz KF, Altman DG, Moher D. CONSORT 2010 statement: updated guidelines for reporting parallel group randomised trials. BMC Med. 2010;8(1):18.

28. Khoshnood A, Carlsson M, Akbarzadeh M, Bhiladvala P, Roijer A, Bodetoft S, Höglund $P$, Zughaft $D$, Todorova L, Erlinge $D$, et al. The effects of oxygen therapy on myocardial salvage in ST elevation myocardial infarction treated with acute percutaneous coronary intervention: the supplemental oxygen in catheterized coronary emergency reperfusion (SOCCER) study. Cardiology. 2015;132(1):16-21.

29. Resuscitation ILCo. 2005 International consensus on cardiopulmonary resuscitation and emergency cardiovascular care science with treatment recommendations. 5. Acute coronary syndromes. Resuscitation. 2005:67(2-3):249-69.

30. Anderson JL, Adams CD, Antman EM, Bridges CR, Califf RM, Casey DE, Chavey WE, Fesmire FM, Hochman JS, Levin TN. ACC/AHA 2007 guidelines for the management of patients with unstable angina/non-ST-elevation myocardial infarction: a report of the American College of Cardiology/ American Heart Association Task Force on Practice Guidelines (Writing Committee to Revise the 2002 Guidelines for the Management of Patients With Unstable Angina/Non-ST-Elevation Myocardial Infarction) developed in collaboration with the American College of Emergency Physicians, the Society for Cardiovascular Angiography and Interventions, and the Society of Thoracic Surgeons endorsed by the American Association of Cardiovascular and Pulmonary Rehabilitation and the Society for Academic Emergency Medicine. J Am Coll Cardiol. 2007;50(7):e1-e157.

31. Pollack CV Jr, Diercks DB, Roe MT, Peterson ED. 2004 American College of Cardiology/American Heart Association quidelines for the management of patients with ST-elevation myocardial infarction: implications for emergency department practice. Ann Emerg Med. 2005;45(4):363-76.

32. Wagner GS, Macfarlane P, Wellens H, Josephson M, Gorgels A, Mirvis DM, Pahlm O, Surawicz B, Kligfield P, Childers R. AHA/ACCF/HRS recommendations for the standardization and interpretation of the electrocardiogram: part VI: acute ischemia/infarction. J Am Coll Cardiol. 2009;53(11):1003-11.

33. Engblom $H$, Tufvesson J, Jablonowski $R$, Carlsson M, Aletras AH, Hoffmann $P$, Jacquier A, Kober F, Metzler B, Erlinge D. A new automatic algorithm for quantification of myocardial infarction imaged by late gadolinium enhancement cardiovascular magnetic resonance: experimental validation and comparison to expert delineations in multi-center, multi-vendor patient data. J Cardiovasc Magn Reson. 2016;18(1):27.

34. Jablonowski R, Engblom H, Kanski M, Nordlund D, Koul S, van der Pals J, Englund E, Heiberg E, Erlinge D, Carlsson M. Contrast-enhanced CMR overestimates early myocardial infarct size: mechanistic insights using ECV measurements on day 1 and day 7. JACC Cardiovasc Imaging. 2015;8(12):1379-89.

35. Heiberg E, Sjögren J, Ugander M, Carlsson M, Engblom H, Arheden H. Design and validation of segment-freely available software for cardiovascular image analysis. BMC Med Imaging. 2010;10(1):1.

36. Eitel I, Desch S, Fuernau G, Hildebrand L, Gutberlet M, Schuler G, Thiele H. Prognostic significance and determinants of myocardial salvage assessed by cardiovascular magnetic resonance in acute reperfused myocardial infarction. J Am Coll Cardiol. 2010;55(22):2470-9.

37. Engblom H, Heiberg E, Erlinge D, Jensen SE, Nordrehaug JE, Dubois-Randé $J$, Halvorsen S, Hoffmann P, Koul S, Carlsson M. Sample size in clinical cardioprotection trials using myocardial salvage index, infarct size, or biochemical markers as endpoint. J Am Heart Assoc. 2016;5(3):e002708.

38. Carlsson M, Ubachs JF, Hedström E, Heiberg E, Jovinge $S$, Arheden $H$. Myocardium at risk after acute infarction in humans on cardiac magnetic resonance: quantitative assessment during follow-up and validation with single-photon emission computed tomography. JACC Cardiovasc Imaging. 2009;2(5):569-76.

39. Atar D, Arheden H, Berdeaux A, Bonnet J-L, Carlsson M, Clemmensen P, Cuvier V, Danchin N, Dubois-Randé J-L, Engblom H. Effect of intravenous TRO40303 as an adjunct to primary percutaneous coronary intervention for acute ST-elevation myocardial infarction: MITOCARE study results. Eur Heart J. 2014;36(2):112-9.

40. Erlinge D, Götberg M, Lang I, Holzer M, Noc M, Clemmensen P, Jensen U, Metzler B, James S, Bötker HE. Rapid endovascular catheter core cooling combined with cold saline as an adjunct to percutaneous coronary intervention for the treatment of acute myocardial infarction: the CHILL-MI trial: a randomized controlled study of the use of central venous catheter core cooling combined with cold saline as an adjunct to percutaneous coronary intervention for the treatment of acute myocardial infarction. J Am Coll Cardiol. 2014;63(18):1857-65.

41. Götberg M, Olivecrona GK, Koul S, Carlsson M, Engblom H, Ugander M, van der Pals J, Algotsson L, Arheden H, Erlinge D. A pilot study of rapid cooling by cold saline and endovascular cooling before reperfusion in patients with ST-elevation myocardial infarction. Circ Cardiovasc Interv. 2010;3(5):400-7.

42. Mythili S, Malathi N. Diagnostic markers of acute myocardial infarction. Biomed Rep. 2015;3(6):743-8.

43. Lønborg J, Vejlstrup N, Kelbæk H, Holmvang L, Jørgensen E, Helqvist S, Saunamäki K, Ahtarovski KA, Bøtker HE, Kim WY. Final infarct size measured by cardiovascular magnetic resonance in patients with ST elevation myocardial infarction predicts long-term clinical outcome: an observational study. Eur Heart J Cardiovasc Imaging. 2012;14(4):387-95.

44. Wu E, Ortiz JT, Tejedor P, Lee DC, Bucciarelli-Ducci C, Kansal P, Carr JC, Holly TA, Lloyd-Jones D, Klocke FJ. Infarct size by contrast enhanced cardiac magnetic resonance is a stronger predictor of outcomes than left 
ventricular ejection fraction or end-systolic volume index: prospective cohort study. Heart. 2008;94(6):730-6.

45. Sepehrvand N, James SK, Stub D, Khoshnood A, Ezekowitz JA, Hofmann R. Effects of supplemental oxygen therapy in patients with suspected acute myocardial infarction: a meta-analysis of randomised clinical trials. Heart. 2018;104(20):1691-8.

46. Chu DK, Kim LH, Young PJ, Zamiri N, Almenawer SA, Jaeschke R, Szczeklik W, Schünemann HJ, Neary JD, Alhazzani W. Mortality and morbidity in acutely ill adults treated with liberal versus conservative oxygen therapy (IOTA): a systematic review and meta-analysis. Lancet. 2018;391(10131): 1693-705.

\section{Publisher's Note}

Springer Nature remains neutral with regard to jurisdictional claims in published maps and institutional affiliations.

Ready to submit your research? Choose BMC and benefit from:

- fast, convenient online submission

- thorough peer review by experienced researchers in your field

- rapid publication on acceptance

- support for research data, including large and complex data types

- gold Open Access which fosters wider collaboration and increased citations

- maximum visibility for your research: over $100 \mathrm{M}$ website views per year

At BMC, research is always in progress.

Learn more biomedcentral.com/submissions 